\title{
O corpo protagonista nas telas verticais: a influência do enquadramento retrato dos smartphones na produção imagética
}

\section{THE PROTAGONISM OF THE BODY IN THE VERTICAL SCREENS: THE INFLUENCE OF THE PORTRAIT FRAMING OF SMARTPHONES IN THE IMAGETIC PRODUCTION}

\section{Wagner Souza e Silva ${ }^{i}$}

ORCID: https://orcid.org/0000-0003-3839-2305

(Universidade de São Paulo, Programa de Pós-Graduação em Ciências da Comunicação e do Departamento de Jornalismo e Editoração da ECA/USP. São Paulo - SP, Brasil)

\section{Carolina Dos Santos Velleii}

ORCID: https://orcid.org/0000-0001-9302-0892

(Universidade de São Paulo, Programa de Pós-Graduação em Ciências da Comunicação e do Departamento de Jornalismo e Editoração da ECA/USP. São Paulo - SP, Brasil)

Recebido em 30/08/2019. Aprovado em 30/01/2020.

\section{Resumo}

A ubiquidade dos smartphones desafia a hegemonia do vídeo com proporções horizontais, historicamente consolidada pelas tradições do cinema e da televisão. $\mathrm{O}$ presente trabalho revisita a trajetória da imagem técnica nos meios de comunicação e destaca a relevância de redes sociais digitais como o Snapchat e o Instagram para a popularização do audiovisual vertical. Para abordar a temática, construímos um percurso bibliográfico que analisa como o formato vertical contribui para o fortalecimento da cultura das selfies e, de forma geral, para o aumento da exposição do corpo humano, que se mostra cada vez mais protagonista no universo imagético.

Palavras-chave: Produção audiovisual. Imagem técnica. Redes sociais digitais. Selfie. Vídeo vertical.

\section{Abstract}

The ubiquity of smartphones challenges the hegemony of video with horizontal proportions, historically consolidated by the traditions of cinema and television. This paper revisits the trajectory of the technical image in the media and highlights the relevance of social networks such as Snapchat and Instagram for the popularization of vertical audio/visual. To address the theme, we built a bibliographic path that analyzes how the vertical format contributes to the strengthening of the culture of selfies and, in general, to the increased exposure of the human body, which is increasingly protagonist in the imaginary universe.

Keywords: Audiovisual production. Technical image. Social networks. Selfie. Vertical video. 


\section{Introdução}

Em janeiro de 2018, a TV Globo deu início a uma campanha chamada 'O Brasil que eu quero', convocando pessoas de todo o Brasil a gravarem vídeos com o celular. "O país inteiro vai dar o seu recado nos telejornais da emissora. Você pode ser o porta-voz da sua cidade", diz o texto explicativo no site do G1, portal de notícias do grupo Globoํ․ No entanto, o que começou como uma iniciativa de jornalismo participativo, passou a render piadas e memes na Internet. Um dos principais motivos: o insistente apelo da emissora para que os vídeos fossem gravados na horizontal.

Ainda na primeira semana de campanha, Tiago Leifert, apresentador da emissora, defendeu o formato vertical no seu perfil pessoal da rede social Twitter. A brincadeira - que supostamente teria desagradado a alta cúpula da TV $\mathrm{Globo}^{2}$ - somada às demais reclamações do público, mostra uma clara dissintonia entre as práticas de vídeo características de dispositivos móveis e a linguagem visual nativa da televisão.

Figura 1 - Post no Twitter do apresentador Tiago Leifert defendendo o vídeo vertical.

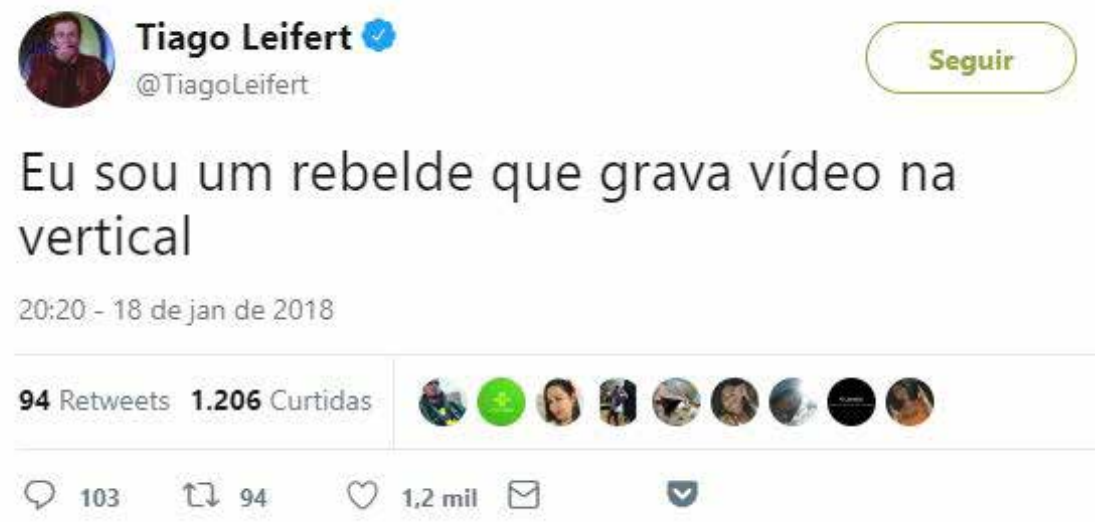

Fonte: Leifert $(2018)^{3}$

\footnotetext{
${ }^{1}$ Disponível em: https://g1.globo.com/vc-no-g1/noticia/que-brasil-voce-quer-para-o-futuro-saiba-como-enviar-o-seu-video.ghtml

${ }^{2}$ Disponível em: https://veja.abril.com.br/blog/radar/brincadeira-de-tiago-leifert-irrita-cupula-da-globo/

${ }^{3}$ LEIFERT, Tiago. Vídeo na vertical. Disponível em: Acesso em: 26 abr. 2020 
Essa 'desordem' de enquadramentos é um sintoma de uma cultura imagética em transformação. A hegemonia da posição horizontal, consolidada pelo cinema e pela televisão, hoje enfrenta a eclosão dos vídeos verticais, em consequência do avanço do uso de smartphones como meio de produção de imagens.

Neste contexto, o Snapchat, um aplicativo para celular, se destaca por ser um dos primeiros a abraçar a ruptura do vídeo no formato vertical em tela cheia dentro dos dispositivos móveis (RYAN, 2018). Criado em 2011, o Snapchat nasceu originalmente como um aplicativo de troca de mensagens, no qual os usuários podiam trocar 'snaps' (termo derivado de snapshot, ou foto instantânea em inglês), compostos principalmente por fotos de autorretrato, as populares selfies ${ }^{4}$. O suporte para vídeo surgiu em 2012. O aplicativo continuou a popularizar o formato vertical com o surgimento do Snapchat Stories, em 2013, uma atualização que permitiu a postagem de fotos e vídeos em sequência, disponíveis por 24 horas no perfil dos usuários. Como os snaps, o formato stories também ocupa toda a tela do smartphone na vertical (BELL, 2017).

De olho na crescente popularidade do Snapchat, a partir de 2015, outras plataformas como YouTube, Facebook, Twitter e Instagram, cederam ao modo retrato nos celulares e também passaram a oferecer a exibição em tela inteira para vídeos gravados na vertical. A exclusividade no formato de narrativa de stories, introduzido pelo Snapchat, foi desbancada pelo seu concorrente Instagram em agosto de 2016. Desde então, outras empresas também inseriram a dinâmica das histórias visuais verticais em suas aplicações para celulares (NEAL; ROSS, 2018).

Este trabalho tem como objetivo explorar mudanças que levaram ao crescimento dos vídeos verticais e, em conjunto, localizar pontos de contato entre esse fenômeno e a contínua exposição da intimidade como espetáculo (SIBILIA, 2016). Para isso, na primeira parte deste artigo será traçado um breve retrospecto da história da imagem técnica, de forma a caracterizar as mudanças nas proporções de tela, partindo da influência da pintura nos primórdios da fotografia até o advento dos smartphones. Em seguida, apresentaremos características que fizeram dos telefones móveis agentes cruciais para a popularização do vertical no audiovisual. Por fim, observando a influência de redes sociais digitais como o Snapchat e o Instagram, analisaremos como o foro contribui para a crescente exposição do corpo que toma conta das telas.

\footnotetext{
4 O que diferencia o conceito de selfie utilizado neste artigo ao de um autorretrato feito por uma câmera comum é o fato de essa experiência ser feita através de tecnologias particulares, tais como o smartphone e uma plataforma online de troca de imagens, gerando condições que não apenas mediam, como também produzem subjetividades no mundo contemporâneo (JONES, 2002; TIFENTALE; MANOVICH, 2015).
} 


\section{O quadro das imagens técnicas na era pré-smartphones}

A imagem técnica ${ }^{5}$, suporte dos vídeos verticais, começa a ser idealizada ainda no Renascimento italiano, no século XV. Nesse momento, os artistas visuais começam a desenvolver dispositivos destinados a dar objetividade e coerência ao trabalho artístico (MACHADO, 2002, p. 224). Dessa forma, os equipamentos que garantiam a perspectiva das imagens e que criavam uma ilusão de profundidade sobre a tela plana contribuíram diretamente para o surgimento, no século XIX, das imagens técnicas exclusivamente produzidas por aparelhos, condição essa que Flusser (2002) supõe para a própria definição do termo.

Assim, a fotografia consolida a simbiose entre tecnologia e imagem, porém, como "filha legítima da iconografia renascentista" (MACHADO, 2002, p. 227), a técnica fotográfica herda muitos aspectos da linguagem artística das pinturas.

Desde suas origens, a fotografia praticou muito o enquadramento, com a intenção de imitar a pintura. De modo mais fundamental, a imagem fotográfica (e a imagem fílmica) foi concebida como enquadrada, limitada por um quadro (moldura), de forma aliás variável (AUMONT; MARIE, 2010, p. 249).

O cinema, que assim como a fotografia, também surge através de múltiplas contribuições, tem em sua origem uma grande diversidade de formatos de tela. A primeira padronização da proporção da tela do cinema (ou, pelo termo técnico em inglês aspect ratio ${ }^{6}$ ), coube ao engenheiro escocês William Dickson, enquanto trabalhava nos laboratórios de Thomas Edison. Inventor de um dos primeiros protótipos de câmeras cinematográficas, Dickson personalizou os filmes recém-lançados por Eastman Kodak com a medida de $35 \mathrm{~mm}$ de largura e perfurações nas duas extremidades laterais, que resultaram um formato central retangular nas proporções de 4:3 (ou 1,33:1). Em 1892,

${ }^{5}$ Machado restringe o conceito de imagem técnica "a um campo de fenômenos visuais e audiovisuais em que a intervenção da técnica produz uma diferença no universo das imagens" (MACHADO, 2002, p. 224).

${ }^{6}$ O aspect ratio pode ser expresso tanto por uma relação de dois números inteiros, como 4:3 (para cada 4 unidades de largura, 3 unidades de altura), como pelo resultado de sua fração decimal, como 1,33:1. (ZETTL, 2010) 
essa medida foi escolhida como padrão para o cinema mudo até a inclusão da faixa de áudio na lateral do filme, que transformou a proporção para 1,15:1, deixando-a mais quadrada.

Os engenheiros cinematográficos descreveram a nova imagem quadrada como estática, não-dinâmica e inadequada para o conteúdo dramático típico de filmes, o qual era visto como envolvendo ações e elementos horizontais em vez de verticais. Sugestões de que o formato quadrado era esteticamente desagradável foram reforçadas por argumentos baseados na psicologia da visão humana, que considera um campo de visão de aproximadamente 8 unidades por 5 (ou 1,6:1); a proporção de 1,15:1 não correspondia a esse campo de "visão natural". Ao visitar Hollywood em 1930, na época desses debates, Sergei Eisenstein falou em nome da nova imagem quadrada, elogiando-a por seu potencial dinâmico, mas seus argumentos aparentemente tiveram pouco impacto na comunidade científica ou nos membros da indústria cinematográfica (BELTON, 1992, p. 44, tradução nossa7).

Devido a tais reclamações, em 1932, a Academia de Artes e Ciências Cinematográficas votou a favor de restaurar o antigo tamanho, fazendo leves alterações para atingir uma proporção de 1,37:1 (apesar de o formato continuar a ser referido pela indústria como 1,33:1).

Com a popularização dos televisores na década de 1950 - que utilizavam quase o mesmo aspect ratio do cinema (4:3) - e o desenvolvimento de novas tecnologias na produção de películas, outros formatos de tela começaram a surgir para que o cinema pudesse chamar novamente a atenção do público para as salas (BELTON, 1992). As projeções ficam, então, com telas mais largas (widescreen), oferecendo uma maior impressão de imersão aos espectadores.

Se a história do cinema pudesse ser comparada, digamos, à pintura, então antes do advento da filmagem widescreen em 1953, o cinema existia como uma operação restrita ao formato retrato com um lugar privilegiado para

\footnotetext{
7 "Motion picture engineers described the new, square image as static, nondynamic, and inappropriate for typical motion picture dramatic content, which was seen to involve horizontal rather than vertical actions and elements. Suggestions that the squarish format was aesthetically unpleasing were reinforced by arguments based on the psychology of human vision, which takes in a field of view that is roughly 8 units by 5 (or 1.6:1); the 1.15:1 aspect ratio did not match this field of "natural vision." Visiting Hollywood in 1930 at the time of these debates, Sergei Eisenstein spoke out on behalf of the new square-shaped image, praising it for its dynamic potential, but his arguments apparently had little impact on either the scientific community or members of the film industry."
} 
composições verticais. Isso não quer dizer que imagens em paisagem não fossem possíveis ou que a mise-en-scène orientada lateralmente não existisse. Textos cinemáticos, com bem poucas exceções, eram compostos em apenas uma forma: o quase quadrado Academy ratio. Antes de 1953, o formato do cinema é o do retrato. Depois de 1953, o formato do cinema é o da paisagem. $\mathrm{O}$ widescreen foi simplesmente uma ruptura com as normas estilísticas anteriores porque a forma do próprio quadro foi drasticamente reconfigurada (COSSAR, 2009, p. 5, tradução nossa) ${ }^{8}$.

A partir do desenvolvimento das tecnologias digitais na década de 1990, é escolhida, como padrão para as projeções HDTV (High Definition Television), a proporção 16:9 (1,78:1) - definida a partir de um meio termo entre os formatos 1,33:1 (padrão da TV) e 2,35:1 (uma média dos formatos típicos de cinema) que poderia manter a proporção original dos conteúdos de ambas as mídias sem a necessidade de barras pretas horizontais ou verticais muito extravagantes (ZETTL, 2011).

Mas foi justamente com a popularização da World Wide Web como interface de acesso ao conteúdos audiovisuais digitais, que o retângulo horizontal perderia a sua hegemonia, já que as práticas envolvendo a microinformática definiram a rolagem vertical como lógica de varredura na exploração de conteúdos de páginas eletrônicas (MONFRINATO \& SOUZA E SILVA, 2017, p. 72). E a consolidação dos smartphones como dispositivos de acesso a essa realidade de produção e consumo imagéticos, acentuaria ainda mais o confronto entre as orientações vertical e horizontal dos quadros.

\section{O advento do smartphone e o estigma de "amadorismo" dos vídeos verticais}

Os celulares passaram a ter a proporção 16:9 apenas em 2012. Antes disso, os formatos variaram entre 3:2 e 5:3. Atualmente, algumas empresas já inovam com o formato 18:9, com telas ainda mais altas na posição retrato (ANGELOV, 2018). Porém, no caso dos smartphones, é preciso observar outras características além das proporções

\footnotetext{
8 'If cinema's history can be compared to, say, painting, then prior to 1953 's advent of widescreen filmmaking, cinema existed as a portrait-only operation with a premium placed on vertical compositions. This is not to say that landscape shots were not possible or that laterally oriented mise-en-scène did not exist. Cinematic texts, with very few exceptions, were composed in only one shape: the almost square Academy ratio. Before 1953, cinema's shape is that of portraiture; after 1953, cinema's shape is landscape. Widescreen was quite simply a breakfrom previous stylistic norms because the shape of the frame itself was drastically reconfigured."
} 
de sua tela. Além de funcionar como câmera, o equipamento integra ambientes sociais de compartilhamento de informações com possibilidades de comunicação que podem leválo a ser considerado uma extensão do corpo físico (BAIRRAL, 2018). Os smartphones

trazem, além da mobilidade (característica de outros artefatos, o telefone sem fio, por exemplo), a convergência (várias possibilidades midiáticas em um só recurso) e a ubiquidade (a possibilidade de navegar por vários espaços graças à conectividade) (BAIRRAL, 2018, p. 81).

Além disso, conforme pontua Manovich (2007), a tendência de estetização de ferramentas de informação, que começa nos anos 1990, transforma a experiência de interagir com um celular em um evento sedutor. Toda a interface dos smartphones é construída para que o equipamento seja segurado com uma mão e manipulado na vertical. "A gravação na horizontal minimiza a experiência sedutora" (RYAN, 2018, p. 225, tradução nossa ${ }^{9}$ ), já que é preciso rotacioná-lo em $90^{\circ}$ e segurá-lo, muitas vezes, com as duas mãos para dar estabilidade, o que fere em grande medida a ergonomia ágil e despojada que o aparelho supõe agenciar. Assim, a captura de imagem em formato vertical tende a ser imediatamente mais intuitiva, pois está alinhada com o mesmo posicionamento do aparelho quando utilizado para as diversas outras funções.

A controvérsia dos formatos está relacionada à transmissão dos vídeos fora do ambiente em que são produzidos (RYAN, 2018). Uma gravação com orientação vertical toma toda a tela de um celular quando segurado na posição retrato. No entanto, na televisão ou no monitor de um computador, o mesmo vídeo demanda adaptações, já que ocupa apenas uma parte da tela, deixando grandes bordas laterais vazias. Da mesma forma, um vídeo na posição paisagem demanda a orientação horizontal do celular. Quem o assiste sem virar o smartphone fica com uma visão minúscula do conteúdo.

Graças à disseminação dos celulares dotados de câmeras, a entrada dos novos 'cinegrafistas' nas redes sociais digitais começou a desafiar o cânone horizontal do audiovisual e, por muitos anos, o conflito entre formatos e suportes se manteve. Até 2008, o YouTube, uma das maiores plataformas de vídeo da Internet, usava o mesmo padrão dos monitores de computador na época, a proporção 4:3.10

\footnotetext{
9 "Horizontal shooting minimizes the seductive experience."
}

${ }^{10}$ Em 2008, a empresa comunicou a adoção do formato widescreen, mas ainda mantendo compatibilidade com vídeos no formato 4:3. Ver em: https://youtube.googleblog.com/2008/11/bigger-isn-always-better-but-in-this.html 
Em 2012, no blog oficial do YouTube, a empresa anunciou o YouTube Capture, aplicativo lançado para gravação e upload de vídeos na plataforma. O comunicado apresentou um diferencial do produto: ele lembraria o usuário a rotacionar o celular para a posição horizontal para a filmagem, pois assim os vídeos "pareceriam de alta qualidade e livres da 'Síndrome do Vídeo Vertical'"'11. A referência foi retirada de um vídeo, também de 2012, envolvendo dois bonecos de pelúcia, do canal Glove and Boots no YouTube, que ganhou milhões de visualizações ao alertar o público sobre os riscos de uma 'doença moderna’: a Síndrome do Vídeo Vertical (SVV) ${ }^{12}$. Na sátira, é possível ver reproduzidas algumas das críticas mais usadas pelas pessoas que consideram errado o modo retrato de vídeo, com argumentos em defesa do formato horizontal.

A possibilidade de exibição de vídeos verticais em tela cheia só veio em 2015, ocasião em que o YouTube divulgou ter mais da metade de sua audiência provindo de dispositivos móveis ${ }^{13}$. Também em 2015, outros aplicativos, como o Snapchat e o Periscope, começaram a enfatizar o enquadramento vertical para dispositivos móveis. Com a mudança nos hábitos de navegação das pessoas - dos computadores para os smartphones -, produtores editoriais e publicitários passaram, nos últimos anos, a criar conteúdos exclusivos com a orientação vertical.

Operando na área de aplicativos móveis, essas plataformas obscurecem as conceituações tradicionais de mídia amadora e profissional, hospedando conteúdo gerado pelo usuário, bem como trabalho interno e/ou comissionado e material de marketing em um espaço virtual onde a distinção entre eles é pouco clara (NEAL; ROSS, 2018, p. 153, tradução nossa ${ }^{14}$ ).

\footnotetext{
11 "YouTube Capture will remind you to rotate your phone to a horizontal position for filming, so your videos look high-quality and free of 'Vertical Video Syndrome'. " Disponível em: https://youtube.googleblog.com/2012/12/film-and-share-videos-instantly-with.html

${ }^{12}$ Em janeiro de 2019 o vídeo "Vertical Video Syndrome - A PSA" foi retirado no YouTube e transferido para o Vimeo. Disponível em: https://vimeo.com/313458699

${ }^{13}$ Disponível em: https://youtube.googleblog.com/2015/07/youtube-mobile-updates-2015.html

14 “Operating in the arena of mobile apps, these platforms blur traditional conceptualisations of amateur and professional media by hosting user-generated content as well as in-house and/or commissioned work and marketing material in a virtual space where the distinction between them is often unclear."
} 


\section{A potência estética dos vídeos verticais}

Como visto anteriormente no exemplo da sátira sobre a 'Vertical Video Syndrome', é frequente a associação do vídeo filmado no modo retrato a um desconhecimento técnico de quem opera a câmera. Porém, McLuhan $(1969$, p. 285) nos lembra que "o artista deve sempre jogar e experimentar com novas maneiras de estruturar a experiência, mesmo que a maioria da audiência prefira continuar em suas velhas e fixas atitudes perceptivas". Projetos com audiovisual vertical são trabalhados no ramo da arte, transitando no circuito artístico como uma atividade de vanguarda. Já existem festivais cinematográficos exclusivos para essas produções, como o Vertical Film Festival (Austrália) ${ }^{15}$, Vertifilm (República Tcheca) ${ }^{16}$ e Vertical Cinema (itinerante) ${ }^{17}$.

No texto do programa de abertura da primeira edição do Vertical Film Festival, em 2014, o diretor do festival, Adam Sébire, fez um retrospecto sobre a história das proporções nas telas, questionando a resistência na atualidade dos artistas produtores de cinema em aceitar a possibilidade de filmes verticais.

Até o advento do cinema, a maioria das artes visuais não se adequava a nenhuma orientação ou proporção. Embora o enquadramento vertical fosse predominante nas telas e papiros asiáticos, e na Europa antes do interesse em retratar paisagens que surge no final do século XIV, as pinturas apresentavam-se essencialmente em todas as formas e tamanhos. Algumas pinturas escapavam completamente da moldura em forma de afrescos, enquanto a câmera obscura vinha entregando imagens em movimentos circulares durante milênios. Então, por que a chamada 'sétima arte' insistir em tal padronização? (SÉBIRE, 2014, tradução nossa ${ }^{18}$ ).

Por ser um formato quase não utilizado na indústria cinematográfica, Sébire cita a dificuldade de encontrar equipamentos cinematográficos adequados para as gravações de vídeos verticais. Apesar dos empecilhos, reforça que a escolha pelo formato de moldura

${ }^{15}$ Disponível em: https://verticalfilmfestival.org/about/

${ }^{16}$ Disponível em: http://www.vertifilms.com/

${ }^{17}$ Disponível em: http://verticalcinema.org/events/

18 "Till the advent of cinema most visual art didn't conform to any one orientation or aspect ratio. Though vertical framing was predominant in Asian screens and scrolls and in Europe prior to the late 1400s interest in depicting landscapes, paintings essentially came in all shapes and sizes. Some paintings escaped the frame altogether in the form of frescoes, while the camera obscura had been delivering circular moving images for millennia. So why should the so-called 'seventh art' insist on such standardisation?" 
deve ser baseada principalmente no assunto a ser tratado:

[...] eles (os verdadeiros criadores verticais) precisam superar os problemas dos aparelhos projetados para capturar, editar e filmar imagens horizontais. (Mesmo o manual do projetor HD do Festival inclui um alerta do fabricante para nunca o virar de lado!). Mas, superando esses desafios, eles se tornaram os mais recentes pioneiros do cinema. Em última análise, a escolha do cineasta de fazer um filme horizontal, vertical, circular ou quadrado deve ser puramente determinada pelo assunto e o que estamos tentando dizer (SÉBIRE, 2014, tradução nossa19).

Durante a edição de 2016 do MIPTV (Marché International des Programmes de Télévision), em Cannes, na França, Jean-Charles Granjon ganhou o prêmio do júri em uma competição de vídeos verticais por sua obra 'Impact'. O curta, de três minutos de duração, mostra o momento de impacto de um mergulhador profissional com a água, desde o seu pulo de um penhasco até o seu encontro com o mar.

Figuras 2, 3 e 4: frames extraídos do curta Impact, de Jean-Charles Granjon.
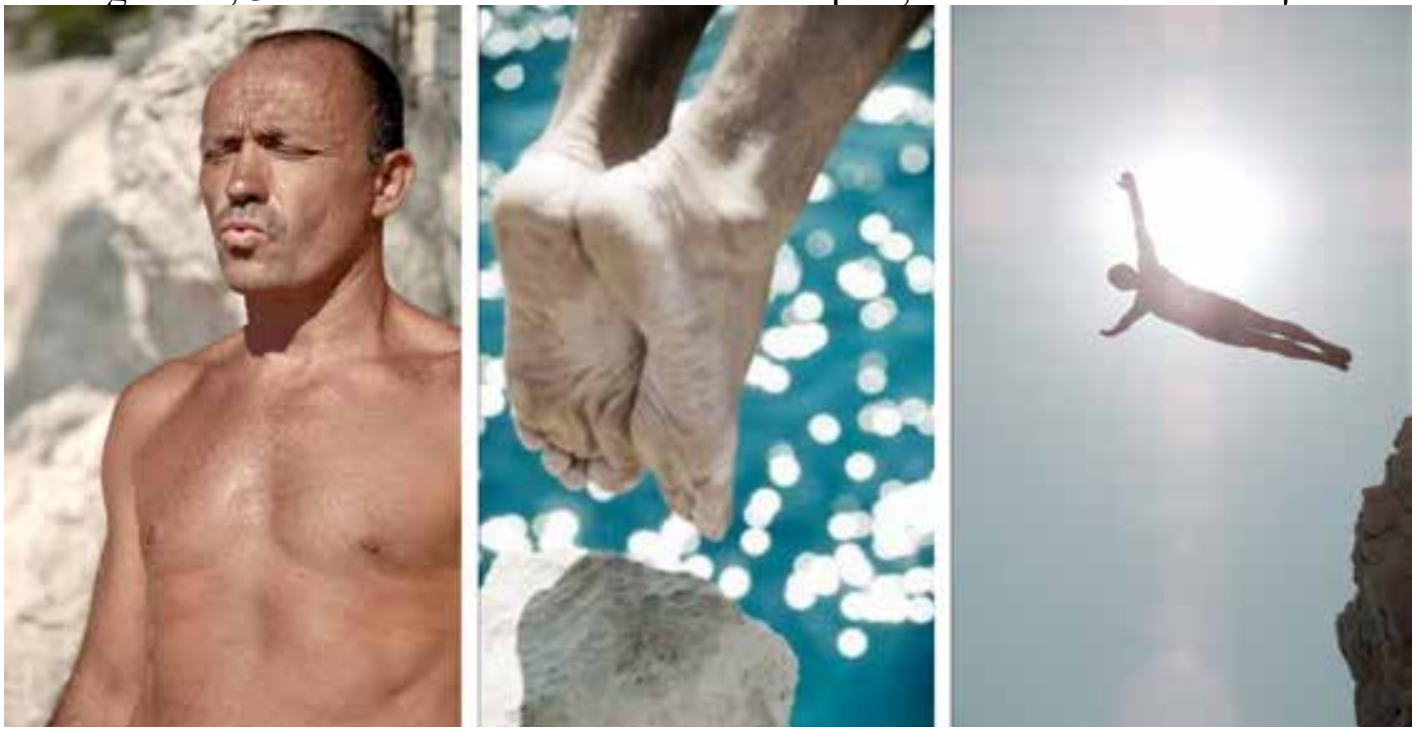

Fonte: https://vimeo.com/147742438

\footnotetext{
19 "True vertical creators shun such dogma by composing their shots with the vertical frame in mind. To do so they have to overcome the problems of apparatus designed for capturing, editing and screening horizontal images. (Even the manual for the Festival's HD projector includes a surly warning from the manufacturer never to turn it on its side!) But in surmounting these challenges they've become cinema's latest pioneers. Ultimately the filmmaker's choice of whether to make a horizontal, vertical, circular or square film should purely be determined by the subject matter and what we're trying to say."
} 
Em entrevista à organização do festival, Granjon falou sobre as possibilidades estéticas abertas à exploração no formato vertical:

A maneira como nos comportamos é principalmente horizontal. [...] Mas alguns assuntos fazem sentido na dimensão vertical. Mergulho, como em 'Impact', é um assunto óbvio, mas quando fugimos das dimensões convencionais, como o espaço, o mar ou o céu, esse local não é mais horizontal, então temos uma escolha a fazer (MARTIN, 2016, tradução nossa) ${ }^{20}$.

Percebe-se, com isso, que o enquadramento pode alterar a forma como nos relacionamos com uma imagem, já que "a realidade não é vertical nem horizontal: os dois retângulos são apenas as fôrmas que o fotógrafo utiliza para registrar aquilo que vê" (PULS, 2016). Puls registra que as linhas horizontais passam a impressão de imobilidade e tranquilidade, visto que sua posição deitada está relacionada às noções de repouso, sono e morte. Já as linhas verticais, por sua vez, passam a ideia de dinamismo e intensidade, uma vez que a posição em pé lembra, segundo esse mesmo pensamento, o movimento, a energia e a ação.

Na história das artes plásticas e da fotografia, o formato de tela vertical foi marcado pelo seu uso em quadros com destaque para as figuras humanas, o chamado formato 'retrato'. Enquanto isso, o formato horizontal ficou reconhecido por sua vocação para retratar cenas mais abertas, as 'paisagens'.

A paisagem constitui uma janela para o mundo, uma abertura através da qual podemos observar os acontecimentos. O retrato, por sua vez, lembra uma porta para o mundo, uma abertura que nos convida a entrar nos acontecimentos. Assim, quando definimos o campo visual, projetamos nossa disposição subjetiva - passiva ou ativa - no objeto (PULS, 2016, grifos do autor).

Borges (2003) classifica o formato retrato como emblemático para se entender a natureza polissêmica e híbrida da imagem fotográfica, guardando muitas semelhanças de propósito com o seu uso também na pintura. Para Borges, o retrato serve ao interesse de transcendência do indivíduo do anonimato para o reconhecimento, servindo como prova

20 "The way we behave is mainly horizontal. [...] But some subjects make sense in the vertical dimension. Diving, like in Impact, is an obvious subject, but when we escape from conventional dimensions, like space, sea or sky, that space isn't horizontal anymore, so we have a choice to make". 
material da presença humana e, ao mesmo tempo, alimentando a memória individual e coletiva.

As linhas de fuga dos retratos, quase sempre a meio-corpo, atraem o olhar do expectador para os detalhes da roupa, das mãos e da expressão de seu olhar. O fotógrafo-artista quer, fundamentalmente, exprimir uma tese corrente no mundo da pintura, na qual o retrato artístico mais que informar, deveria representar. (BORGES, 2003, p.44)

Essa potencialidade do retrato fortalece seu uso em redes sociais digitais, como o Snapchat, onde reinam as selfies. Em uma entrevista à imprensa, Nick Bell, vice-presidente de conteúdo da empresa reforçou esse conceito sobre o fato de o enquadramento ressaltar a figura do corpo humano. "Chama-se modo retrato por uma razão [...]. Muito do que assistimos é sobre pessoas” (STERN, 2016, tradução nossa ${ }^{21}$ ).

\section{O protagonismo do 'eu' nas telas verticais}

Assim como o 'rebelde' Tiago Leifert do começo deste artigo, outras pessoas também não estão se dobrando ao uso horizontal dos smartphones. De acordo com o MOVR (Mobile Overview Report) (SCIENTIAMOBILE, 2019), entre os meses de outubro e dezembro de $2018,82,5 \%$ dos visitantes de sites centrados em vídeo (como o YouTube) mantinham seu smartphone na orientação retrato, mesmo sabendo que a maior parte do conteúdo era oferecido no formato paisagem. E é principalmente entre os jovens que as plataformas com formatos nativamente verticais fazem mais sucesso. Nos Estados Unidos, 78\% das pessoas entre 18 e 24 anos estão no Snapchat (PEW RESEARCH CENTER, 2018).

Em um estudo conduzido por Piwek e Joinson (2016) sobre os padrões de uso do Snapchat, descobriu-se que a troca de selfies entre os usuários corresponde à principal atividade exercida dentro do aplicativo. Pelo menos metade dos entrevistados disseram que o último snap enviado era uma foto desse tipo. $\mathrm{O}$ ato de tirar e enviar selfies têm progressivamente se desenvolvido com a proliferação da mídia digital e tornou-se uma prática cultural da atualidade, principalmente entre jovens. Tal fenômeno representa "a of what we watch is about people.", 
triunfante junção entre visibilidade e conexão" (SIBILIA, 2016, p.21). Para Sibilia, o sucesso na disseminação dos smartphones se deve ao alto potencial de articulação que eles oferecem entre subjetividade e sociabilidade.

Além das selfies, outro exemplo que integra visibilidade à conexão no âmbito dos vídeos verticais é o IGTV, um aplicativo para produções audiovisuais de até uma hora, lançada pelo Instagram em junho de 2018. Aproveitando o crescimento do interesse dos usuários pelo modo retrato, a aplicação se propõe a oferecer conteúdo da forma como as pessoas "realmente usam o celular"22. Os vídeos verticais são apresentados em tela inteira e começam a passar automaticamente quando o aplicativo é aberto, semelhante ao funcionamento de uma televisão.

Dentro da plataforma, os conteúdos são divididos por canais, assim como no YouTube, mas com o destaque para a figura do 'criador': "Qualquer um pode ser um criador - você pode subir seu próprio vídeo no aplicativo IGTV ou na Internet para começar seu canal”23. É possível interagir com comentários, dar 'curtidas' nos vídeos, enviar o conteúdo para amigos por mensagem privada, deslizar para o lado para descobrir novos canais e trocar entre as opções 'Para você', 'Seguindo', 'Popular' e 'Continue Assistindo'.

Flusser (2008), ao aprofundar o fenômeno das imagens técnicas, discorre sobre o futuro do artista, que passaria a ser visto como jogador que brinca com pedaços disponíveis de informação. O jogo produtivo de informações, para ele, aconteceria dentro de uma rede dialógica, tornada tecnicamente viável graças à telemática e a seus gadgets. Temos, no cenário de ubiquidade de telas atual, a transcrição do pensamento flusseriano nas redes sociais digitais e nos smartphones. Conseguimos enxergar os criadores mencionados pelo Instagram como os novos jogadores da sociedade, os produtores de imagens e informações que se autorreferenciam a todo o tempo nesse universo imagético. "O futuro jogador, o futuro apertador de teclas, se deixará tomar pela vertigem da criatividade e será engolido pelo seu jogo" (FLUSSER, 2008, p. 144).

Com os criadores no centro e com a profusão do fenômeno das selfies, a exposição da figura humana é uma forte presença nas telas dos smartphones:

\footnotetext{
${ }^{22}$ It's built for how you actually use your phone, so videos are full screen and vertical". Disponível em: https://instagram-press.com/blog/2018/06/20/welcome-to-igtv/

23 "Anyone can be a creator - you can upload your own IGTV videos in the app or on the web to start your own channel.". Disponível em: https://instagram-press.com/blog/2018/06/20/welcome-to-igtv/
} 
Nesta cultura das aparências, do espetáculo e da visibilidade, já não parece haver motivos para mergulhar naquelas sondagens em busca dos sentidos abissais perdidos dentro de si mesmo. Em lugar disso, tendências exibicionistas e performáticas alimentam a procura de um efeito: o reconhecimento nos olhos alheios e, sobretudo, o cobiçado troféu de ser visto. Cada vez mais é preciso aparecer para ser. Pois tudo aquilo que permanecer oculto, fora do campo da visibilidade - seja dentro de si, trancado no lar ou no interior do quarto próprio -, corre o risco de não ser interceptado por olho algum. E, de acordo com as premissas básicas da sociedade do espetáculo e da moral da visibilidade e da conexão, se ninguém vê alguma coisa não há como garantir que isso de fato exista (SIBILIA, 2016, p. 151, grifos da autora).

Na sociedade do espetáculo, descrita pelo francês Guy Debord, as relações sociais passam a ser mediadas por imagens. Pode-se, com isso, observar no contexto atual que não só somos mediados por imagens, como também somos a imagem, pois na busca pela aparência nas redes sociais digitais e nos vídeos verticais, toda a "realidade individual se tornou social" (DEBORD, 2003, p.13).

Tanto a visão de jogador de Flusser como o fenômeno do protagonismo da imagem focada no ser humano também podem ser compreendidos através do conceito do capitalismo artista. O termo é usado pelo francês Gilles Lipovetsky para caracterizar o sistema que conseguiu criar "um império estético que cresce a cada dia: o do espetáculo e do entertainment que se apresenta como arte de massa e que se faz veículo de um consumo transestético distrativo" (LIPOVETSKY; SERROY, 2015, p. 261). O estudioso, que considera o momento vivido pela sociedade como a era do hiperespetáculo (com base em um conceito atualizado da expressão cunhada por Debord), acredita que a sociedade da tela generalizada criou um hiperespectador, interativo e conectado permanentemente, que fabrica e difunde uma profusão de imagens. "Hoje, os indivíduos se pensam em termos de imagens, e eles próprios se põem em cena nas redes sociais ou diante das câmeras" (LIPOVETSKY; SERROY, 2015, p. 263). 


\section{Considerações finais}

Com a produção e o consumo crescentes de filmes verticais, em conjunto com os avanços tecnológicos nas câmeras dos celulares, a posição retrato não é mais 'a posição dos amadores', mas sim uma opção que se mostra válida dentro do contexto dos smartphones e que também merece ser respeitada enquanto opção estética para produtores e artistas do audiovisual. A tela do celular, em conjunto com a ergonomia pensada para o seu uso, convida as pessoas a segurarem o equipamento na posição vertical. Sendo essa a escolha mais cômoda, não causa espanto que o paradigma da imagem horizontal esteja sofrendo mudanças.

Ao mesmo tempo, a recorrente exposição dos corpos nas telas, sobretudo por intermédio das selfies, acaba por favorecer esta situação de embates entre as proporções do quadro. De certa forma, é possível notarmos esse fenômeno como um novo momento de afirmação do 'eu' perante o mundo: ao preterir a posição paisagem e optar pela tela vertical da posição retrato, que classicamente está alinhada com a representação imagética dos corpos, usuários parecem assumir sua condição como imagem, condição esta que parece ser fundamental para os jogos e trocas que se estruturam na tela contemporânea.

\section{Referências}

ANGELOV, Yordan. Sunday debate: Classic 16:9 vs. Taller screen ratios. Jun 2018. Disponível em: https://www.gsmarena.com/sunday debate classic 169 screen ratio vs_tall_screen_ratio-news-31429.php. Acesso em: 15 jun. 2018.

AUMONT, Jacques; MARIE, Michel. Dicionário Teórico e Crítico de Cinema. São Paulo: Papirus Editora, 2010.

BAIRRAL, Marcelo. Dimensões a considerar na pesquisa com dispositivos móveis. Estudos Avançados, São Paulo, v. 32, n. 94, p. 81-95, Dez. 2018. Disponível em: https://dx.doi.org/10.1590/s0103-40142018.3294.0007. Acesso em: 16 abr. 2019.

BELL, Karissa. Snapchat's biggest updates so far. Fev. 2017. Disponível em: https:// mashable.com/2017/02/04/snapchat-updates-five-year/\#N75YEYdZniqM. Acesso em: 7 jan. 2019 
BELTON, John. Widescreen Cinema. Cambridge, MA: Harvard University Press, 1992.

BORGES, Maria Eliza L. História \& fotografia. Belo Horizonte: Autêntica, 2003.

CANELLA, Gino. Video goes vertical: Local news videographers discuss the problems and potential of vertical video. Electronic News, v.12, n. 2, p. 75-93. Jun 2018. Disponível em: https://journals.sagepub.com/doi/abs/10.1177/1931243117705417. Acesso em: 15 jan. 2019.

COSSAR, Harper. The Shape of New Media: Screen Space, Aspect Ratios, and Digitextuality. Journal of Film and Video, v. 61, n. 4, p. 3-16. 2009. Disponível em: https://www.jstor.org/stable/20688644. Acesso em: 23 mar. 2019.

DEBORD, Guy. A Sociedade do Espetáculo. Rio de Janeiro: Contraponto, 1997.

FLUSSER, Vilém. O universo das imagens técnicas: Elogio da superficialidade. São Paulo: Annablume, 2008.

FLUSSER, Vilém. Filofia da Caixa Preta. Rio de Janeiro: Relume Dumará, 2002.

JONES, Amelia. 'The "Eternal Return": Self-Portrait Photography as a Technology of Embodiment. Signs: Journal of Women in Culture and Society, v. 27, n. 4, p. 947 978. 2002. Disponível em: https://www.jstor.org/stable/10.1086/339641. Acesso em 4 jun. 2018.

LIPOVETSKY. G.; SERROY, J. A estetização do mundo: viver na era do capitalismo artista. São Paulo: Companhia das Letras, 2015.

MACHADO, Arlindo. Pré-cinemas e pós cinemas. 2. ed. Campinas: Papiros, 2002.

MANOVICH, Lev. A interação como evento estético. Lumina: revista da Faculdade de Comunicação da UFJF, Juiz de Fora: UFJF, v.1, n.1. Disponível em: http://ojs2.ufjf. emnuvens.com.br/lumina/article/view/20988. Acesso em: 15 jan. 2019.

MANOVICH, Lev; TIFENTALE, Alise. Selfiecity: Exploring Photography and SelfFashioning in Social Media. In: BERRY, David M.; DIETER, Michael (ed). Postdigital Aesthetics: Art, Computation and Design. (Palgrave Macmillan: 2015), p. 109-122.

MARTIN, James. Interview: Vertical film, "a new form of storytelling”. Abr 2016. Disponível em: https://mipblog.com/2016/04/interview-miptv-vertical-video-pioneersspotlight/. Acesso em: 27 jul. 2018.

MCLUHAN, Marshall. Os Meios de Comunicação como Extensões do Homem, São Paulo: Cultrix, 1969. 
MONFRINATO, Bárbara.; SOUZA E SILVA, Wagner. O Instagram e as narrativas de desenquadramento fotográfico. Revista de Estudos de Gestão, Informação e Tecnologia (Regit). Itaquaquecetuba(SP): Fatec. v. 7, n.1, pp 69-81, 2017. Disponível em http:// www.revista.fatecitaqua.edu.br/index.php/regit/article/view/REGIT7-ART5/pdf 78. Acesso em: 22 ago. 2019.

NEAL, Dave.; ROSS, Miriam. Mobile Framing: Vertical Videos from User-Generated Content to Corporate Marketing. In: SCHLESER, M.; BERRY, M. (Ed.). Mobile Story Making in an Age of Smartphones. Cham: Springer International Publishing. p. 151-160. 2018. Disponível em: https://doi.org/10.1007/978-3-319-76795-6_15 . Acesso em: 15 jan. 2019.

PEW RESEARCH CENTER. Social Media Use in 2018. Mar 2018. Disponível em: https://www.pewinternet.org/2018/03/01/social-media-use-in-2018/ Acesso em: 15 jan. 2019.

PIWEK, Lukasz; JOINSON, Adam. "What do they snapchat about?" Patterns of use in time-limited instant messaging service. Computers in Human Behavior. v. 54. p. 358 367. Jan 2016. Disponível em: https://doi.org/10.1016/j.chb.2015.08.026. Acesso em: 23 mar 2019.

PULS, Mauricio. Retrato ou paisagem? Ou: Por que giramos a câmera? Jan 2016. Disponível em: https://revistazum.com.br/radar/retrato-ou-paisagem/ . Acesso em: 27 jul. 2018.

RYAN, Kathleen M. Vertical video: rupturing the aesthetic paradigm. Visual Communication. Maio 2018 v. 17, n. 2, p. 245-261. Disponível em: https://journals. sagepub.com/doi/10.1177/1470357217736660. Acesso em: 15 abr. 2019.

SCIENTIAMOBILE. Mobile Overview Report (MOVR). Fev 2019. Disponível em: https://www.scientiamobile.com/wp-content/uploads/2019/02/MOVR-2018-Q4-Final. pdf. Acesso em: 15 jan. 2019.

SÉBIRE, Adam. A Brief History Of Aspect Ratio. 2014 (rev. 2017). Disponível em: https://verticalfilmfestival.org/about/. Acesso: 15 jul 2018.

SIBILIA, Paula. O Show do Eu: A intimidade como espetáculo. 2 ed., rev. Rio de Janeiro: Contraponto, 2016.

STERN, Joanna. Watch Video on Your Phone the Right Way: Vertically. Set 2016. Disponível em: https://www.wsj.com/articles/watch-video-on-your-phone-the-rightway-vertically-1473178832. Acesso em: 15 jul. 2018. 
ZETTL, Herbert. Sight Sound Motion: Applied Media Aesthetics. 6. ed. Boston, MA: Wadsworth Cengage Learning, 2011.

${ }^{i}$ Professor do Programa de Pós-Graduação em Ciências da Comunicação e do Departamento de Jornalismo e Editoração da ECA/USP. E-mail: wasosi@usp.br

ii Mestranda do Programa de Pós-Graduação em Ciências da Comunicação da ECA/USP. E-mail: carolina.vellei@gmail.com 